\title{
Damage Detection of Flexural Member by Estimated Moment Diagram
}

\author{
H.C. Eun ${ }^{*}, 1$ and E.T. Lee ${ }^{2}$ \\ ${ }^{I}$ Department of Architectural Engineering, Kangwon National University, Chuncheon, Korea \\ ${ }^{2}$ Department of Architectural Engineering, Chung-Ang University, Seoul, Korea
}

\begin{abstract}
This study considers an analytical method to detect the damage location from the moment diagram calculated by the external forces and the forces required for obtaining the same deflections as the measurement deflections. The measured deflections must be a part of displacements to restrict the static behavior of the damaged beam. The constraint forces acting at measurement points are derived by minimizing the cost function of the displacement change between the undamaged and damaged beams. It is shown that the damage exists near the location that the moment ratio to be expressed by the moment values of the undamaged and damaged beams increases abruptly. However, closely neighboring damages can be found by increasing the number of finite elements and measurement points. The validity of the proposed method is illustrated in an application.
\end{abstract}

\section{INTRODUCTION}

There has been a lot of research endeavor for damage detection and assessment of structures by the dynamic approach using dynamic test data or the static approach using static test data. Although the dynamic approaches have been developed more actively, the static approaches have advantages to be simpler and comparatively cheaper than the dynamic ones. Thus, the static test data are expected to yield more reliable results than the dynamic approaches.

The static approaches only require the stiffness properties. And the number of transducers for measuring the deflection is far less than the number of degrees of freedom in the finite element model. The measured deflection data may be expanded to estimate the data at full set of degrees of freedom.

The spatially sampled field measured during the dynamic and static testing has been an active area of research for many years. Comparing just the measured partition of the full analytic displacement shapes to the test displacement shapes, most analysis procedures are possible only when there is one-to-one correspondence between the model degrees of freedom and the test measurements.

Sheena et al. (1982) [1] presented an analytical method to assess the stiffness matrix by minimizing the difference between the actual and the analytical stiffness matrix subjected to the measured displacement constraints. Minimizing the difference between the applied and the internal forces, Sanayei and Scampoli (1991) [2] presented a finite element method for static parameter identification of structures by the systematic identification of plate-bending stiffness parameters for a one-third scale, reinforced-concrete pier-deck model. Sanayei and Onipede (1991) [3] provided an analytical method to identify the properties of structural elements from static test data such as a set of applied static forces and another set of measured displacements. Minimizing an index of discrepancy between the model and the measurements,

*Address correspondence to this author at the Department of Architectural Engineering, Kangwon National University, Chuncheon, Korea; Tel: 82-33250-6211; Fax: 82-33-250-6223; E-mail: heechang@kangwon.ac.kr
Banan et al. (1993) [4,5] proposed the mathematical formulations of two least-squares parameter estimators that estimate element constitutive parameters of a finite-element model that corresponds to a real structural system from measured static response to a given set of loads. And they investigated the performance of the force-error estimator and the displacement-error estimator.

Cui et al. (2000) [6] developed a damage detection algorithm based on static displacement and strain. This method has a difficulty in requiring sufficient measurement information and load cases. Choi et al. (2004) [7] developed an elastic damage load theorem and an approach on the damage identification using static displacements. Chen et al. (2005) [8] presented a two-stage damage identification algorithm to use the change of measured static displacement curvature and grey system theory. Bakhtiari-Nejad et al. (2005) [9] presented a method to describe the change in the static displacement of certain degrees of freedom by minimizing the difference between the load vectors of damaged and undamaged structures. Wang et al. (2001) [10] proposed a twostage identification algorithm for identifying the structural damages by employing the changes in natural frequencies and measured static displacements.

Based on the measured deflection data, it is recognized that the structural damage causes the additional deflection at the initial beam structure due to the deterioration of the loadcarrying capacity at the damage portion. Assuming the measured deflection data as the displacement constraints, a set of forces required for satisfying the given constraints can be regarded as the constraint forces. It can be recognized that the deflected curve can be estimated by the action of both external forces and constraint forces. Pandey et al. (1991) [11] stated that once the displacement shapes of a damaged and of the corresponding undamaged structures are identified, the curvature can be obtained by a central difference approximation. The curvature is related to the moment within the elastic range. The damage exists at the position to exhibit the abrupt increase of the curvature or moment due to the deterioration of flexural rigidity.

The purpose of this study is to propose an analytical method to predict the damage location based on the moment 
diagram calculated by both the constraint forces at measurement points and the known external forces. The constraint forces are derived by the equilibrium equation for constrained systems provided by Eun, Lee and Chung (2004) [12]. The validity of the proposed method is illustrated in beam applications.

\section{FORMULATION}

The intact and damaged beams subjected to external forces exhibit different deflection curves. Fig. (1a and 1b) represent deflected shapes of simply supported beams with and without damages, respectively. Measuring the deflections at $m$ different points as shown in Fig. (1a and 1b), the measured deflection of damaged beam slightly increases due to the locally deteriorated flexural rigidity. The same deflection at the measurement points can be obtained by the action of unknown concentrated forces required for the measured deflections at the intact beam as shown in Fig. (1c). Thus, if the forces at the measurement points are properly calculated, the deflection of the damaged beam can be approximately estimated and the damaged location can be found based on the moment diagram drawn by the external as well as constraint forces. In the following, the equilibrium equation and the forces to describe the deflected curve of damaged beam based on measured displacement data are introduced.

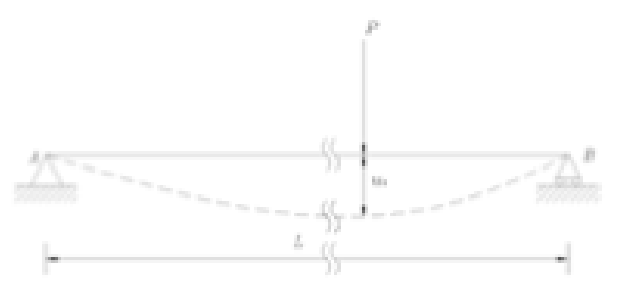

(a)

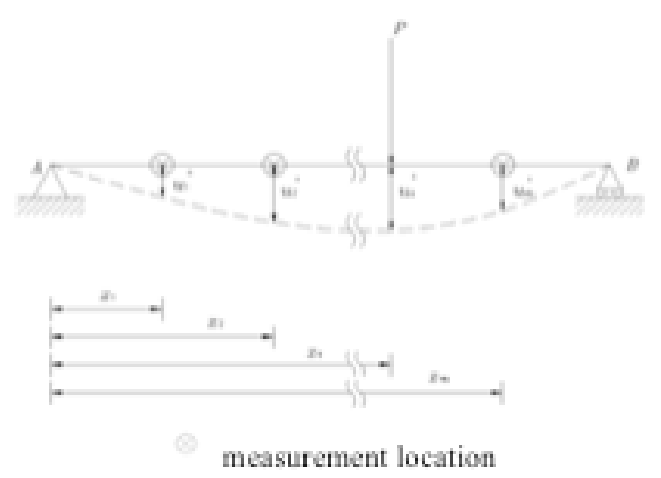

(b)

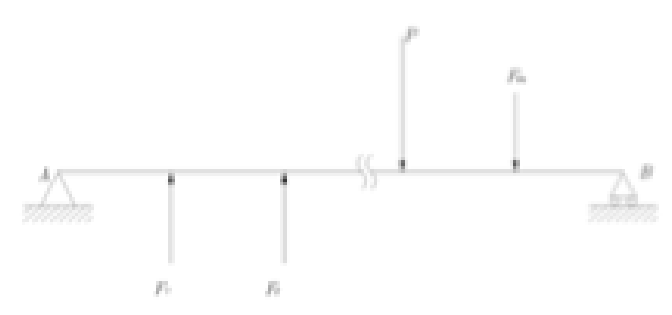

(c)

Fig. (1). Static deflection of undamaged and damaged beams; (a) a simply supported beam subjected to a concentrated force, (b) deflection of damaged beam; (c) constraint forces at the measurement locations.
Let us consider an analytical model for the analysis of static response $u=\left[\begin{array}{llll}u_{1} & u_{2} & \cdots & u_{n}\end{array}\right]^{T}$ formulated as

$\mathrm{F}=\mathrm{Ku}$

where $\mathrm{K}$ is an $n \times n$ positive-definite stiffness matrix and $\mathrm{F}$ denotes an $n \times 1$ applied static force vector. The displacement vector of the undamaged structure, $\mathrm{u}$, can be calculated as

$\mathrm{u}=\mathrm{K}^{-1} \mathrm{~F}$

If the system has been damaged by environmental or accidental loads, the structural parameters are changed and the initial displacements do not correspond with the measured displacements of the damaged beam. The equilibrium equation of the damaged structure under the same applied forces can be written as

$(\mathrm{K}+\Delta \mathrm{K}) \mathrm{u}^{*}=\mathrm{F}$

where $\Delta \mathrm{K}$ represents the variation in the stiffness matrix and $\mathrm{u}^{*}$ is the displacement vector of the damaged structure. Taking the first-order approximation of the displacement vector $\mathrm{u}^{*}$, it can be written by

$$
\mathrm{u}^{*}=(\mathrm{K}+\Delta \mathrm{K})^{-1} \mathrm{~F} \approx\left(\mathrm{K}^{-1}-\mathrm{K}^{-1} \Delta \mathrm{KK}^{-1}\right) \mathrm{F}
$$

or

$\mathrm{Ku}^{*}=\mathrm{F}-\Delta \mathrm{KK}^{-1} \mathrm{~F}$

The second term in the right-hand side of Eqn. (4b) indicates the force vector to explain the additional deflection due to the damage. The forces can be regarded as the forces required for the measured displacement change between undamaged and damaged beam structures or they are interpreted as the forces required for satisfying the measured displacements. The measured displacements partially restrict the static behavior of damaged structure. Thus, the displacement constraints to restrict the static behavior are the measured displacements and can be written as

$\phi_{\mathrm{i}}(\mathrm{u})=\mathrm{c}_{\mathrm{i}} \quad i=1,2, \cdots, \quad m$

where $c_{i} s$ are the measured displacements and they can be expressed in matrix form of

$\mathrm{Au}{ }^{*}=\mathrm{c}$

The cost function for predicting the deflection of full set of degrees of freedom from the measured deflection data can be established as

$J=\frac{1}{2}\left(\mathrm{u}-\mathrm{u}^{*}\right)^{T} \mathrm{~K}\left(\mathrm{u}-\mathrm{u}^{*}\right)$

Minimizing a quadratic function of the displacement difference between undamaged and damaged structures of Eqn. (7) with respect to the damaged displacement vector, the displacements of damaged structure provided by Eun, Lee and Chung (2004) [12] are derived as

$\mathrm{u}^{*}=\mathrm{u}+\delta \mathrm{u}=\mathrm{u}+\mathrm{K}^{-1 / 2}\left(\mathrm{AK}^{-1 / 2}\right)^{+}(\mathrm{c}-\mathrm{Au})$ 
where $\delta u$ denotes the displacement variation due to the damage and ' + ' denotes the Moore-Penrose inverse ${ }^{1}$. The derivation is introduced in Appendix. Premultiplying both sides of Eqn. (8) by the stiffness matrix K, it yields

$\mathrm{Ku}^{*}=\mathrm{Ku}+\mathrm{K}^{1 / 2}\left(\mathrm{AK}^{-1 / 2}\right)^{+}(\mathrm{c}-\mathrm{Au})$

where the second term in the right-hand side denotes the additional forces to act on the original structure besides the initially applied force vector F. From Eqns. (4a) and (8), the displacement variation is defined as

$\delta \mathrm{u}=-\mathrm{K}^{-1} \Delta \mathrm{KK}^{-1} \mathrm{~F}=\mathrm{K}^{-1 / 2}\left(\mathrm{AK}^{-1 / 2}\right)^{+}(\mathrm{c}-\mathrm{Au})$

It is apparent that the damage is caused by the action of the additional forces. The additional forces defined as the constraint forces are calculated as

$\mathrm{F}^{\mathrm{c}}=\mathrm{K}^{1 / 2}\left(\mathrm{AK}^{-1 / 2}\right)^{+}(\mathrm{c}-\mathrm{Au})$

If the structure is not damaged, the additional forces do not require and the displacement variation $\delta \mathrm{u}=\mathrm{u}^{*}-\mathrm{u}$ must be zero. And it can be observed that the constraint forces increase with the increase in the displacement difference $\mathrm{c}-\mathrm{Au}$ at the measurement points.

The validity of the derived constraint forces can be evaluated by substituting the constraint force vector of Eqn. (11) into the constraints of Eqn. (6). The constraints of Eqn. (6) can be modified as

$\mathrm{AK}^{-1} \mathrm{~K}(\mathrm{u}+\delta \mathrm{u})=\mathrm{AK}^{-1}\left(\mathrm{~F}+\mathrm{F}^{\mathrm{c}}\right)=\mathrm{c}$

Utilizing Eqn. (11) into Eqn. (12), it follows that

$\mathrm{AK}^{-1} \mathrm{~F}+\mathrm{AK}^{-1} \mathrm{~K}^{1 / 2}\left(\mathrm{AK}^{-1 / 2}\right)^{+}\left(\mathrm{c}-\mathrm{AK}^{-1 / 2} \mathrm{~K}^{1 / 2} \mathrm{u}\right)=\mathrm{c}$

$\mathrm{Au}+\mathrm{AK}^{-1 / 2}\left(\mathrm{AK}^{-1 / 2}\right)^{+}\left(\mathrm{c}-\mathrm{AK}^{-1 / 2} \mathrm{~K}^{1 / 2} \mathrm{u}\right)=\mathrm{c}$

$\mathrm{AK}^{-1 / 2}\left(\mathrm{AK}^{-1 / 2}\right)^{+} \mathrm{c}=\mathrm{c}$

where

$\mathrm{AK}^{-1 / 2}\left(\mathrm{AK}^{-1 / 2}\right)^{+} \mathrm{AK}^{-1 / 2}=\mathrm{AK}^{-1 / 2}$.

Premultiplying both sides of the last equation of Eqn. (13) by $\left(\mathrm{AK}^{-1 / 2}\right)^{+}$, it is observed that the constraint equation of Eqn. (6) is satisfied. The deflected curve of the damaged beam can be predicted by the displacement equation of Eqn. (8) or based on the constraint forces of Eqn. (11).

\section{DAMAGE DETECTION BY MOMENT DIAGRAM}

Beam is a flexural member which flexural mode or flexural curvature governs its mechanical behavior. When the beam is elastic, the moment is proportional to the curvature:

\footnotetext{
${ }^{1}$ Letting $\mathrm{A}^{T}=\left[\begin{array}{llll}\mathrm{a}_{1}^{T} & \mathrm{a}_{2}^{T} & \mathrm{~L} & \mathrm{a}_{m}^{T}\end{array}\right]$, where $\mathrm{a}_{i}$ is the $i-$ th $1 \times n$ row vector and assuming that all row vectors are independent, the pseudo inverse of the matrix can be calculated as$$
\mathrm{A}^{+}=\frac{\mathrm{a}_{1}^{T}}{\mathrm{a}_{1} \mathrm{a}_{1}^{T}}+\frac{\mathrm{a}_{2}^{T}}{\mathrm{a}_{2} \mathrm{a}_{2}^{T}}+\mathrm{L}+\frac{\mathrm{a}_{m}^{T}}{\mathrm{a}_{m} \mathrm{a}_{m}^{T}}=\sum_{i=1}^{m} \frac{\mathrm{a}_{i}^{T}}{\mathrm{a}_{i} \mathrm{a}_{i}^{T}}
$$

$M_{o}(x)=(E I)_{o} \phi_{o}(x)$

where $M_{o},(E I)_{o}$ and $\phi_{o}$ are the moment, flexural rigidity and curvature of the initial beam, respectively. The occurrence of the damage yields the deteriorated flexural rigidity $(E I)_{d}$, and the moment $M_{d}$ and the curvature $\phi_{d}$ abruptly increase. The damage detection method based on the displacement curvature provided by Pandey et al. can be certified by the moment distribution from the relation of Eqn. (14).

The moment diagram can be drawn by the constraint forces calculated by Eqn. (11) at the measurement points and the known external forces. The damage is located near the point to exhibit the abrupt increase of moment. As an application to verify the proposed damage detection method, we consider a simple cantilever beam in Fig. (2). It is assumed that the beam is modeled using the finite element method with 50 beam elements that the length of each element is $20 \mathrm{~mm}$. The beam has a length of $1 \mathrm{~m}$, a gross cross-section of $75 \mathrm{~mm} \times 9 \mathrm{~mm}$ and the damage section of $25 \mathrm{~mm} \times 9 \mathrm{~mm}$. The damage degree was established as the $33 \%$ strength of the initial second moment of inertia. The beams were damaged at locations of 200,400 and $600 \mathrm{~mm}$, respectively, from the fixed end and they have a single damage or multiple damages. The deflection of the beam was measured at 180 , 360,540 and $720 \mathrm{~mm}$ from the fixed end. The beam was subjected to a concentrated force $97 \mathrm{~N}$ at the free end.

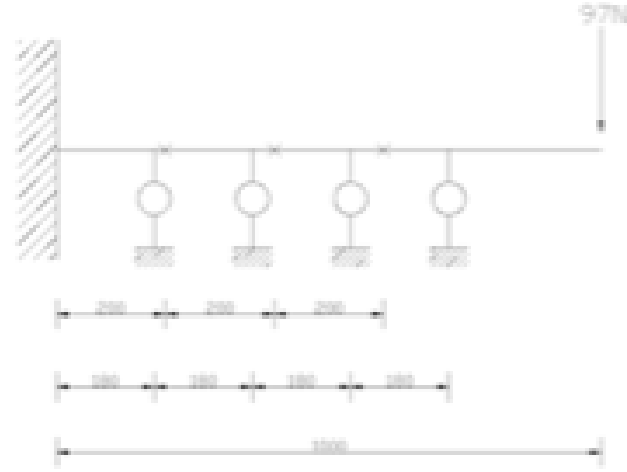

$$
\text { measurement location, } \mathrm{x} \text {; damage location }
$$

Fig. (2). A cantilevered beam subjected to a concentrated force (unit: $\mathrm{mm}$ ); and represent the damage location and measurement location.

Table 1 represents the deflection data measured at four points and the forces for satisfying the measured deflection data calculated by Eqn. (11). The forces for the measured deflection are exhibited in Fig. (3) and they show different force direction and values according to the damage location. In the plots, the (+) values indicate the lower force direction $(\downarrow)$ and the (-) the upper force direction $(\uparrow)$. As the damage occurs near the fixed end, it is observed that larger forces are required. Fig. (4) exhibits the moment diagram drawn by the forces shown in Fig. (3). In the plots, $M_{o}$ denotes the moment of the original beam and $M_{d}$ represents the moment of the damaged beam subjected to the calculated forces. If the 


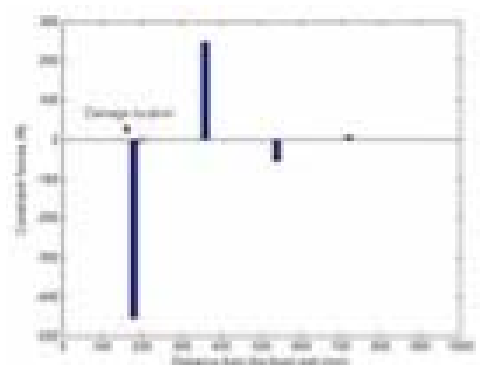

(a)

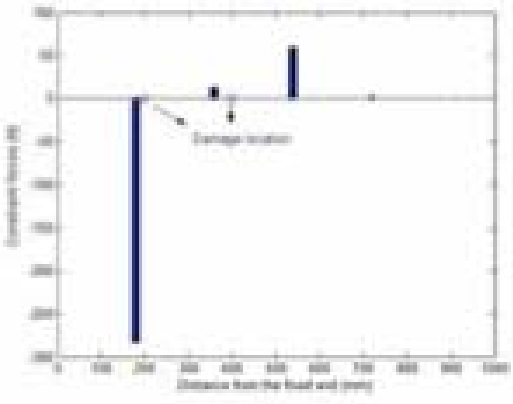

(d)

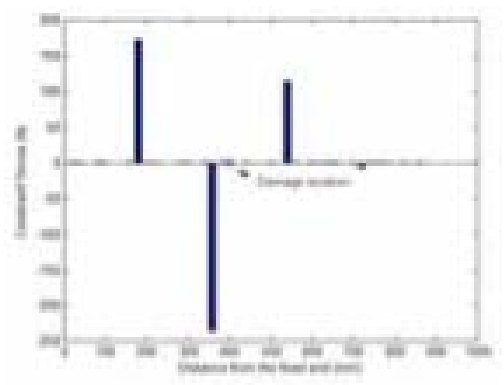

(b)

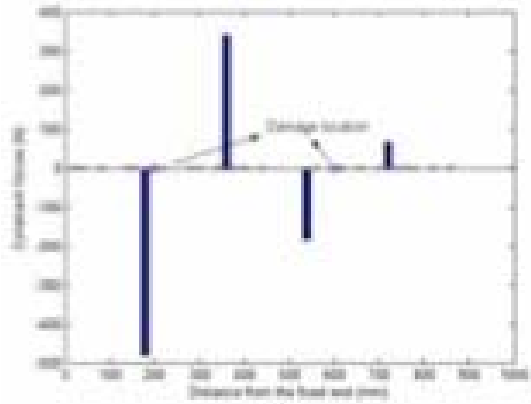

(e)

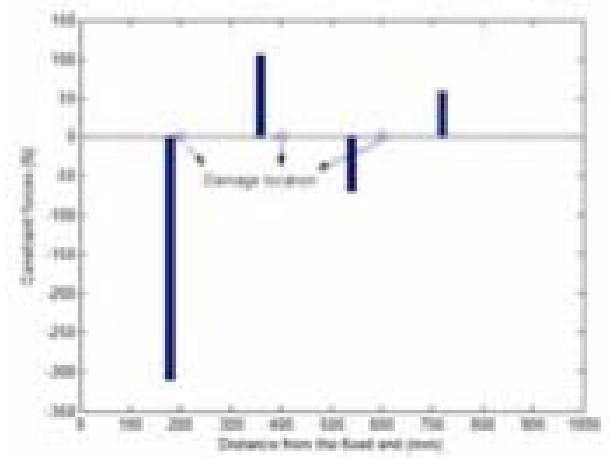

(g)

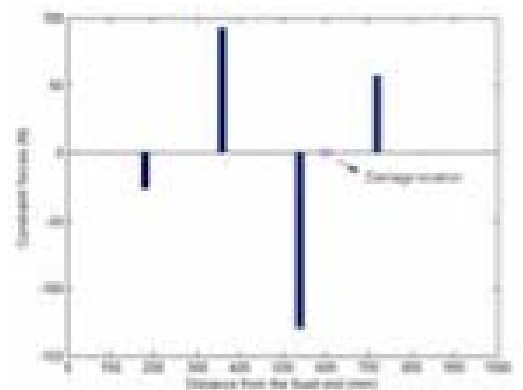

(c)

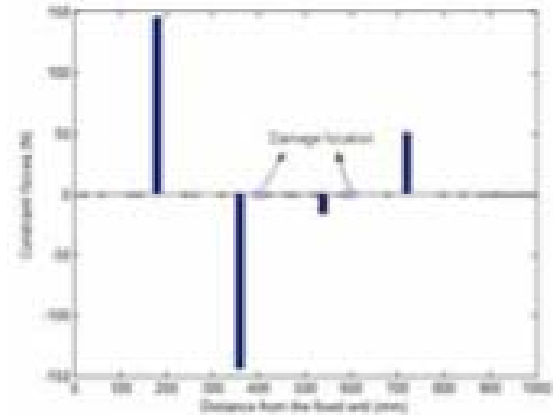

(f)

Fig. (3). Constraint forces at measurement points; (a) D-2, (b) D-4, (c) D-6, (d) D-2,4, (e) D-2,6, (f) D-4,6, (g) D-2,4,6.

Table 1. Measured Deflection Data and Required Constraint Forces

\begin{tabular}{|c|c|c|c|c|c|}
\hline Beam & Damage Locations (mm) & \multicolumn{4}{|c|}{ Deflection $(\mathbf{m m}) /$ forces $(\mathbf{N})$} \\
\hline D-2 & 200 & $23.38 / 9.0$ & $14.29 /-54.1$ & $6.83 / 248.5$ & $1.66 /-454.5$ \\
\hline D-4 & 400 & $22.39 /-6.8$ & $13.45 / 113.9$ & $6.23 /-235.9$ & $1.66 / 171.8$ \\
\hline D-2,4 & 200,400 & $24.26 / 2.2$ & $14.69 / 59.8$ & $6.83 / 12.6$ & $1.66 /-282.7$ \\
\hline D-2,6 & 200,600 & $23.61 / 66.1$ & $14.29 /-183.6$ & $6.83 / 340.7$ & $1.66 /-480.9$ \\
\hline D-4,6 & 400,600 & $22.62 / 50.2$ & $13.45 /-15.6$ & $6.23 /-143.7$ & $1.66 / 145.4$ \\
\hline $\mathrm{D}-2,4,6$ & $200,400,600$ & $24.49 / 59.3$ & $14.69 /-69.7$ & $6.83 / 104.8$ & $1.66 /-309.1$ \\
\hline
\end{tabular}




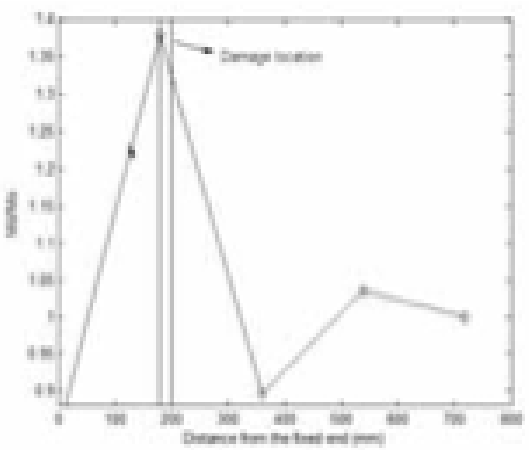

(a)

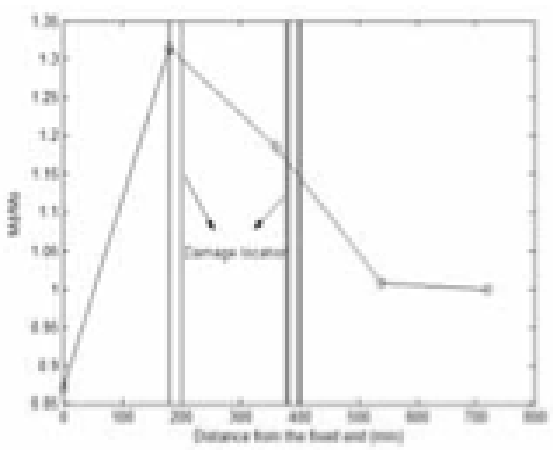

(d)

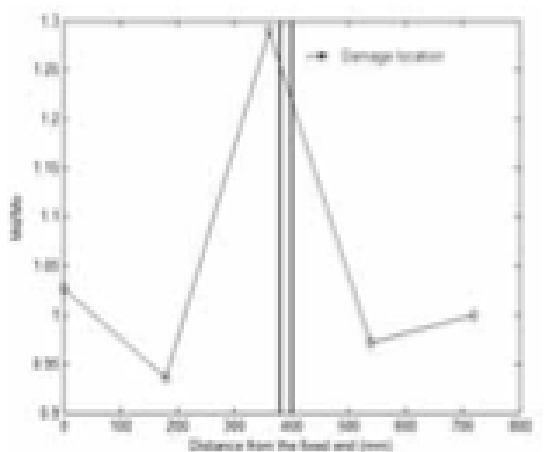

(b)

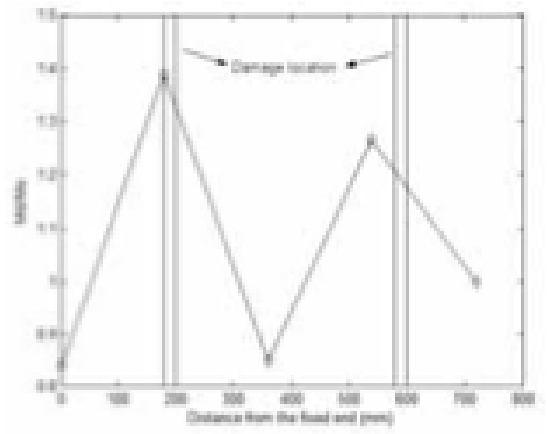

(e)

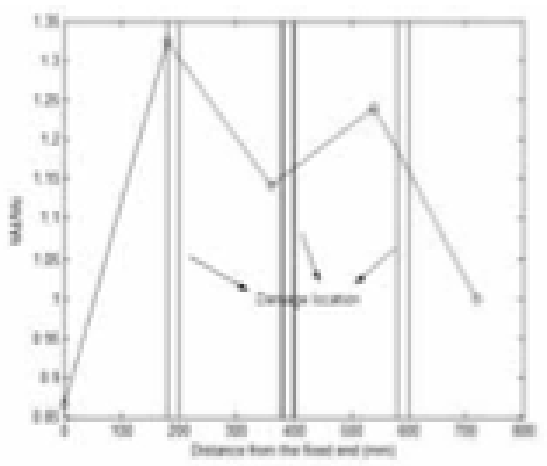

(g)

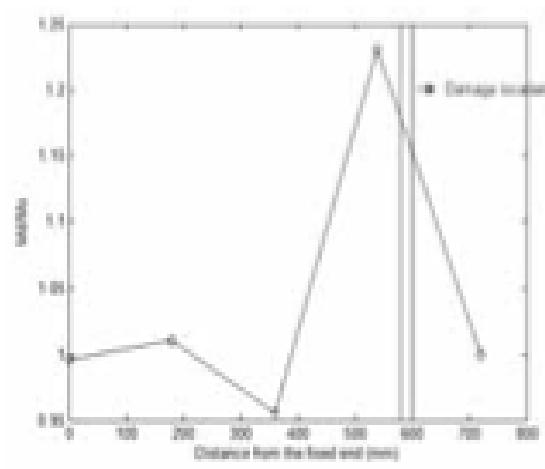

(c)

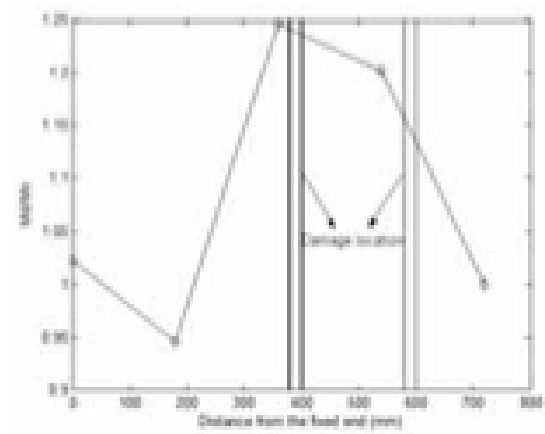

(f)

Fig. (4). Moment ratio; (a) D-2, (b) D-4, (c) D-6, (d) D-2,4, (e) D-2,6, (f) D-4,6, (g) D-2,4,6.

damage locations do not coincide with the measurement locations, the approximate damage location should be detected. If the damage is located at the measurement locations, the damage location can be exactly detected. And if the number of finite elements increases, it will be possible to detect the damage location more closely. As shown by the plots to represent the moment ratio of the beams with a single damage and multiple damages, it is recognized that the damage exists the location to exhibit the moment ratio larger than 1.2. In the beams with closely neighboring multiple damages, it is not easy to distinct the explicit damage location. Fig. (5) represents the constraint forces and moment diagram of the beam D-2,4 modeled as 100 finite elements and eight measurement points. As shown by Fig. (5), it can be expected that the problem can be alleviated by increasing the number of finite element as well as the number of measurement points or assuming that the damages exist above the moment ratio of 1.2. The application exhibits that the proposed method can be widely utilized for the damage detection of flexural beam.

\section{CONCLUSIONS}

The damage of flexural beam can be detected by the displacement curvature as mentioned by Pandey et al. Considering that the moment is proportional to the curvature within the elastic range and using moment distribution or variation, this study proposed an analytical method for the damage detection of beams. Predicting the forces required for satisfying the measured deflection data at the measurement points, the moment diagram was drawn by the calculated forces. Although the abrupt increase of the moment near the damage location can be observed, the damage locations of the beams that the damaged locations do not coincide with the measurement locations can be approximately detected. The damages of the beams which have closely neighboring damages can be identified by increasing the number of finite element and the number of measurement points. It is concluded that the proposed method based on moment diagram can be widely utilized in predicting the damage detection. 


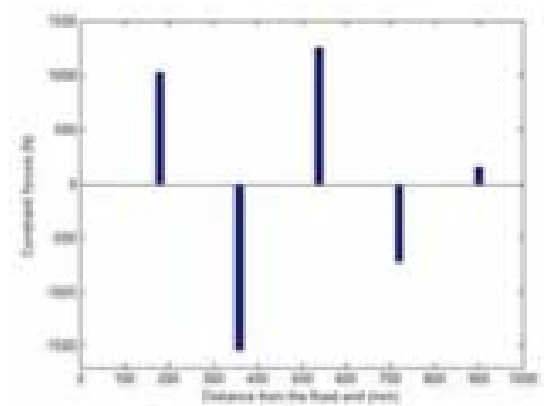

(a)

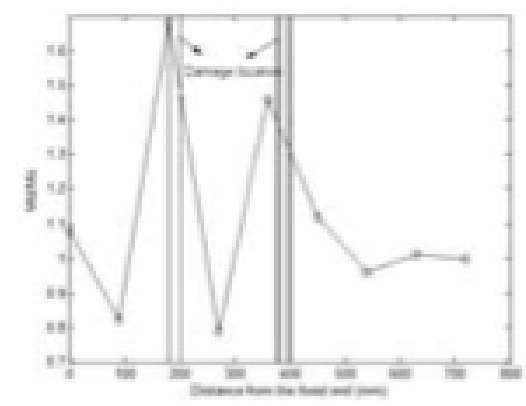

(b)

Fig. (5). Finite element analysis of 100 elements on the beam D-2,4; (a) Constraint forces, (b) Moment ratio.

\section{APPENDIX}

The equilibrium equation for unconstrained structure described by a displacement vector $\hat{\mathrm{u}}=\left[\begin{array}{llll}\hat{u}_{1} & \hat{u}_{2} & \cdots & \hat{u}_{n}\end{array}\right]^{T}$ can be written as

$\mathrm{F}=\mathrm{Kû}$

where $\mathrm{F}$ is the $n \times 1$ nodal force vectors, and $\mathrm{K}$ is the $n \times n$ positive definite stiffness matrix. Assume that the structure is subjected to $m$ displacement constraints

$\phi_{i}(\mathrm{u})=c_{i}, \quad i=1, \quad 2, \quad \cdots \quad m$.

or

$\mathrm{Au}=\mathrm{b}$,

where $\mathrm{A}$ is an $m \times n$ matrix and $\mathrm{u}$ is an $n \times 1$ actual displacement vector. The two displacement vectors exhibit different displacements due to the constraints.

Defining the displacements at actual state as $\mathrm{u}=\hat{\mathrm{u}}+\Delta \mathrm{u}$, the change of the potential energies can be written as

$$
\begin{array}{r}
\Delta \pi=\frac{1}{2}(\hat{\mathrm{u}}+\Delta \mathrm{u})^{T} \mathrm{~K}(\hat{\mathrm{u}}+\Delta \mathrm{u})-(\hat{\mathrm{u}}+\Delta \mathrm{u})^{T} \mathrm{~F} \\
-\frac{1}{2} \hat{\mathrm{u}}^{\mathrm{T}} \mathrm{K} \hat{\mathrm{u}}+\hat{\mathrm{u}}^{T} \mathrm{~F}
\end{array}
$$

The equilibrium equation of the constrained system and the constraint equation can be modified as

$\mathrm{F}=\mathrm{Ku}+\mathrm{K} \Delta \mathrm{u}$

$\mathrm{A}(\hat{\mathrm{u}}+\Delta \mathrm{u})=\mathrm{b}$

Expressing the constraint force vector $\mathrm{F}^{\mathrm{c}}$, Eqn. (A5) is written as

$\mathrm{F}=\mathrm{K} \hat{u}+\mathrm{F}^{\mathrm{c}}$

For this derivation, Eqn. (A6) is modified as

$\mathrm{A} \Delta \mathrm{u}=\mathrm{b}-\mathrm{A} \hat{\mathrm{u}}$

In order to utilize Eqn. (A8) into Eqn. (A4), Eqn. (A8) is modified as

$\mathrm{AK}^{-1 / 2} \mathrm{~K}^{1 / 2} \Delta \mathrm{u}=\mathrm{b}-\mathrm{A} \hat{u}$
From the fundamental property of generalized inverse matrix and its solution ${ }^{*}$, the solution with respect to $\mathrm{K}^{1 / 2} \Delta \mathrm{u}$ can be obtained as

$$
\mathrm{K}^{1 / 2} \Delta \mathrm{u}=\left(\mathrm{AK}^{-1 / 2}\right)^{+}(\mathrm{b}-\mathrm{A} \hat{\mathrm{u}})+\left[\mathrm{I}-\left(\mathrm{AK}^{-1 / 2}\right)^{+}\left(\mathrm{AK}^{-1 / 2}\right)\right] \mathrm{y}
$$

where ' + ' denotes the generalized inverse matrix and $y$ is an arbitrary vector.

Minimizing the variation of total energy with respect to $\Delta \mathrm{u}$, it follows that

$\frac{\Delta \pi}{\Delta \mathrm{u}}=\mathrm{K}^{1 / 2}(\hat{\mathrm{u}}+\Delta \mathrm{u})-\mathrm{F}=0$.

Equation (A11) can be rewritten as

$\mathrm{K}^{1 / 2} \Delta \mathrm{u}=\mathrm{F}-\mathrm{K}^{1 / 2} \hat{\mathrm{u}}$.

From Eqns. (A10) and (A12), the following equation is obtained.

$$
\begin{aligned}
& \mathrm{K}^{1 / 2} \Delta \mathrm{u}=\left(\mathrm{AK}^{-1 / 2}\right)^{+}(\mathrm{b}-\mathrm{A} \hat{\mathrm{u}})+ \\
& +\left[\mathrm{I}-\left(\mathrm{AK}^{-1 / 2}\right)^{+}\left(\mathrm{AK}^{-1 / 2}\right)\right] \mathrm{y}=\mathrm{F}-\mathrm{K}^{1 / 2} \hat{\mathrm{u}}
\end{aligned}
$$

Letting $\mathrm{Q}=\left[\mathrm{I}-\left(\mathrm{AK}^{-1 / 2}\right)^{+}\left(\mathrm{AK}^{-1 / 2}\right)\right]$, solving Eqn. (A13) with respect to $\mathbf{y}$, and the fundamental properties of generalized inverse matrix ${ }^{* *}$, it follows that

$$
\mathrm{y}=\left(\mathrm{AK}^{-1 / 2}\right)^{+}\left(\mathrm{AK}^{-1 / 2}\right) \mathrm{z}
$$

where $\mathbf{z}$ is another arbitrary vector.

Substitution of Eqn. (A14) into Eqn. (A13) and arranging the result, it follows that

\footnotetext{
"The general solution of $\mathrm{Ax}=\mathrm{b}$, where $\mathrm{A}$ is $m \times n$ matrix, $\mathrm{x}$ and $\mathrm{b}$ are $n \times 1$ and $m \times 1$ vectors, respectively, can be written as$$
\mathrm{x}=\mathrm{A}^{+} \mathrm{b}+\left[\mathrm{I}-\mathrm{A}^{+} \mathrm{A}\right] \mathrm{d},
$$

where $\mathrm{I}$ is $n \times n$ identity matrix and $\mathrm{d}$ is $n \times 1$ arbitrary vector.

$\left(\mathrm{AK}^{-1 / 2}\right)^{+}\left(\mathrm{AK}^{-1 / 2}\right)\left(\mathrm{AK}^{-1 / 2}\right)^{+}=\left(\mathrm{AK}^{-1 / 2}\right)^{+}$,

$\mathrm{Q}^{+}=\left[\mathrm{I}-\left(\mathrm{AK}^{-1 / 2}\right)^{+}\left(\mathrm{AK}^{-1 / 2}\right)\right]^{+}=\mathrm{Q}, \mathrm{Q}^{+} \mathrm{Q}=\mathrm{Q}$
} 
$\mathrm{K}^{1 / 2} \Delta \mathrm{u}=\left(\mathrm{AK}^{-1 / 2}\right)^{+}(\mathrm{b}-\mathrm{A} \hat{\mathrm{u}})$

and premultiplying both sides of Eqn. (A15) by $\mathrm{K}^{1 / 2}$, the constraint force is obtained as

$$
\mathrm{F}^{\mathrm{c}}=\mathrm{K} \Delta \mathrm{u}=\mathrm{K}^{1 / 2}\left(\mathrm{AK}^{-1 / 2}\right)^{+}(\mathrm{b}-\mathrm{A} \hat{\mathrm{u}})
$$

Substituting Eqn. (A16) into Eqn. (A7), the equilibrium equation of constrained structure is derived as

$$
\mathrm{F}=\mathrm{K} \hat{\mathrm{u}}+\mathrm{K}^{1 / 2}\left(\mathrm{AK}^{-1 / 2}\right)^{+}(\mathrm{b}-\mathrm{A} \hat{u})
$$

or

$$
\mathrm{u}=\hat{\mathrm{u}}+\mathrm{K}^{-1 / 2}\left(\mathrm{AK}^{-1 / 2}\right)^{+}(\mathrm{b}-\mathrm{A} \hat{\mathrm{u}})
$$

\section{REFERENCES}

[1] Z. Sheena, A. Unger, A. Zalmanovich, "Theoretical stiffness matrix correction by static test results", Israel Journal of Technology, vol. 20, pp. 245-253, 1982.

[2] M. Sanayei, S.F. Scampoli, "Structural element stiffness identification from static test data", Journal of Engineering Mechanics, vol. 117(5), pp. 1021-1036, 1991

[3] M. Sanayei, O. Onipede, "Damage assessment of structures using static test data", AIAA Journal, vol. 29(7), pp.1174-1179, 1991.
[4] M.R. Banan, M.R. Banan, K.D. Hjelmstad, "Parameter estimation of structures from static response. I: Computational aspects", Journal of Structuctural Engineering, vol. 120(11), pp. 3243-3258, 1993.

[5] M.R. Banan, M.R. Banan, K.D. Hjelmstad, "Parameter estimation of structures from static response. II: Numerical simulation studies", Journal of Structuctural Engineering, vol. 120(11), pp. 32593283, 1993.

[6] F. Cui, W.C. Yuan, J.J. Shi, "Damage detection of structures based on static response", Journal of Tongji University, vol. 281, pp. 5-8, 2000.

[7] I.Y. Choi, J.S. Lee, E. Choi, H.N. Cho, "Development of elastic damage load theorem for damage detection in a statically determinate beam", Computers \& Structures, vol. 82, pp. 2483-2492, 2004.

[8] X.Z. Chen, H.P. Zhu, C.Y. Chen, "Structural damage identification using test static data based on grey system theory", Journal of Zhe jiang University Science, vol. 6A(*), pp. 790-796, 2005.

[9] F. Bakhtiari-Nejad, A. Rahai, A. Esfandiari, "A structural damage detection method using static noisy data", Engineering Structures, vol. 27, pp. 1784-1793, 2005.

[10] X. Wang, N. Hu, H. Fukunaga, Z.H. Yao, "Structural damage identification using static test data and changes in frequencies", Engineering Structures, vol. 23, pp. 610-621, 2001.

[11] A.K. Pandey, M. Biswas, M.M. Samman, "Damage detection from changes in curvature mode shapes," Journal of Sound and Vibration, vol. 145, pp.321-332, 1991.

[12] H.C. Eun, E.T. Lee, H.S. Chung, "On the static analysis of constrained structural systems", Canadian Journal of Civil Engineering, vol. 31(6), pp. 1119-1122, 2004. 